\title{
Desenvolvimento de competências de servidores na administração pública brasileira
}

Helena Kerr do Amaral

\section{Introdução}

Temos um grande desafio na administração pública brasileira: aumentar a capacidade de governo na gestão das políticas públicas no Brasil. O aperfeiçoamento permanente de servidores poderá contribuir muito para a melhoria da qualidade do serviço público. Não é uma demanda interna ao serviço público, mas uma necessidade, quase um imperativo para ampliar a competitividade do País, de forma a assegurar um desenvolvimento sustentável e menos desigual.

Podemos constatar na literatura que existe um alto grau de correlação entre o desempenho econômico e o funcionamento confiável da administração pública (KARMACK, 2004, p.12). Ou seja, uma economia dinâmica depende de eficiência de seu setor público. Isso talvez explique, desde o final dos anos 90, uma certa convergência de ações voltadas para o aumento da eficiência, assim como a preocupação em construir maior capacidade do Estado - a criação de governo eletrônico é exemplo disso. 
O Brasil tem feito grandes avanços na melhoria e aperfeiçoamento de sua administração pública. O "custo Brasil", assunto abordado sempre de forma pejorativa, deixou de freqüentar os jornais com a constância do início dos anos 90, o que não significa, entretanto, que os problemas tenham sido superados. Ainda persistem, por exemplo, gargalos para a exportação, por conta de ineficiência das autoridades portuárias, de licenças para funcionamento ou extinção de empresas que demandam prazos imensos, entre outros, sobretudo na comparação internacional, apesar de grandes investimentos em áreas estratégicas com o uso cada vez mais intensivo de tecnologia da informação.

Mas seria esta uma dificuldade brasileira? Excelência na administração pública é possível? A questão vem sendo discutida mundo afora há décadas. E, apesar das gigantescas dificuldades, a prática mostranos que é possível desenvolver mudanças de hábito, de mentalidade, de estrutura, de comportamento e de regras, que melhoram objetivamente o padrão de qualidade dos serviços públicos. Foi assim em Nova Iorque, com o centro de tecnologia de governo, com forte impacto nos serviços hospitalares; no acordo de dezenas de prefeituras com os sindicatos, no norte dos Estados Unidos, para melhorar a qualidade do ensino público; no "Poupa Tempo" no Estado de São Paulo; nos atuais programas de inclusão social do governo Lula, como o "Bolsa Família"; nos programas de Saúde da Família espalhados pelo País e nos programas de inclusão digital em diversos países, entre eles o Brasil.

No entanto, apesar desse êxito localizado, persiste enorme dissonância entre o mundo real e o prometido pelos governos nos serviços públicos. Os brasileiros, com muita razão, têm uma imagem tão generalizada quanto ruim desses serviços: péssima qualidade e alto custo financeiro e social.

Por trás da ineficiência e da suposta irracionalidade da máquina pública, existem relações de poder, de dominação, muitas vezes embebidas pela política, mas irremediavelmente impregnadas por uma malha de interesses materiais, que diferenciam os grupos dos que ganham mais da imensa maioria da população que perde quase sempre e, por sua fraqueza política e baixa capacidade de formar opinião, recebe um tratamento pasteurizado. A crua racionalidade que fincou raízes em toda a administração pública brasileira sugere a duplicidade de um discurso genérico por mudanças que se traduz, ao mesmo tempo, em uma ferrenha oposição a qualquer mudança efetiva na administração pública.

O problema, evidentemente, não se esgota no funcionalismo. Toca diretamente nas relações autoritárias que ainda marcam Estado e sociedade no Brasil. Relações que sustentam um Estado engessado burocraticamente, com pouca capacidade de gestão, opaco e intransponível para o cidadão comum. Mudar, nesse caso, significa valorizar efetivamente o servidor, melhorar a qualidade e a eficiência dos serviços, diminuir a malha de vantagens cumulativas para alguns poucos e evitar desperdícios. Significa, também, olhar para a administração e para os servidores com outros olhos. Parece fácil. Mas, na língua da política, mudar significa mexer num vespeiro.

É por essa razão que vamos olhar, com atenção especial, para o fator que julgamos crítico para a melhoria do serviço público: o servidor público e sua capacitação para os desafios contemporâneos. Acreditamos que, para que a administração pública brasileira seja, de fato, um dos fatores de riqueza e de 
vantagem competitiva do País, seja imprescindível investir nos servidores. $\mathrm{O}$ fator crítico seria a existência de servidores profissionalizados. Iremos analisar essa questão à luz do contexto em que esta administração foi constituída e apontar as prioridades de desenvolvimento de competências para dar impulso a essa capacitação tão estratégica para a Nação. A ênfase será dada ao desenvolvimento pessoal e organizacional da administração pública federal brasileira.

\section{Características da administração pública brasileira}

A administração pública brasileira tem traços peculiares, historicamente construídos. Destacamos três dimensões que ajudam a entender essas características: o modelo híbrido de carreiras de servidores; o tipo de federalismo brasileiro; e o ambiente em que opera a administração, marcado por grande heterogeneidade social e econômica.

Por não ter completado a construção de uma burocracia weberiana, nunca se consolidou no País o modelo de carreiras, que, para efeito pedagógico, poderíamos dizer que predomina em países como a França, o Japão ou o Canadá. Descrevemos essa especificidade como o modelo híbrido das carreiras de servidores.

Desde a constituição do Estado moderno no Brasil, em meados dos anos 1930, o Departamento de Administração do Serviço Público (DASP) buscava, por meio dos concursos públicos e de planos de cargos e salários detalhados, construir burocracias desse tipo. A crítica à Velha República (1889 - 1930), em que os apadrinhamentos eram freqüentes, levavam a crer que o modelo de carreiras eliminaria os vícios patrimoniais ou clientelistas, tão bem descritos por Raimundo Faoro (2001). Foram feitos diversos movimentos de construção de instituições voltadas para esse fim, mas que lograram resultados parciais apenas. $\mathrm{O}$ Decreto-Lei 200, de 1967, que tratava da organização da administração federal e estabelecia diretrizes para a reforma administrativa, previa a constituição de uma burocracia weberiana.

\section{"Contamos com instituições e serviços de excelência, provas da qualidade e do investimento na \\ formação. Ao mesmo tempo, encontramos ministérios esvaziados, sem equipes permanentes, sem processos de trabalho estruturados e sem memória."}

No início dos anos 70, buscando maior flexibilidade, constituiu-se um modelo híbrido, em que servidores de empresas estatais e de fundações públicas, submetidos ao contrato de trabalho do setor privado, com bons salários, planos de saúde privados e sem estabilidade no emprego, estavam lado a lado com servidores estáveis, com direito a aposentadorias integrais, mas com salários menores. 
A Constituição de 1988 tenta romper com essa dicotomia, criando o Regime Jurídico Único. Só a partir dessa data que o concurso público torna-se, de fato, o meio essencial para ingresso na administração pública brasileira. O concurso público convive, por outro lado, com um grau de liberdade bastante significativo para nomeação de cargos de confiança de livre provimento.

Não temos, contudo, uma administração com a flexibilidade de países como a Suécia, Finlândia ou Nova Zelândia. A administração brasileira expressa, desta forma, uma tensão permanente entre consolidação de carreiras tradicionais e maior flexibilidade. Observa-se indecisão quanto ao modelo desejado, se mais flexível ou mais burocrático. As conseqüências dessa alternância de projetos são ruins para a gestão de pessoas em qualquer das unidades da federação. Ela tem conduzido a fragmentação e tensões entre servidores com direitos e deveres distintos, às vezes exercendo funções semelhantes.

$\mathrm{O}$ embate entre profissionalismo e flexibilidade é uma contradição que não precisaria existir, mas o debate público não tem sido feito adequadamente de modo a construir consensos sobre o perfil da administração pública que se deseja no País. Sobretudo, no que se refere à ocupação de cargos de confiança. Há relativa liberdade para a ocupação de cargos de Direção e Assessoramento Superiores (DAS) no Brasil, especialmente se comparada a países europeus. Mas a maioria desses cargos de livre provimento (60\%) é ocupada por servidores concursados pertencentes ao quadro funcional do Estado brasileiro ${ }^{1}$ (KERCHE, 2006).

Outra característica importante para compreender a administração pública brasileira é o modelo de federalismo do País. Nosso olhar, neste artigo, é para a situação criada a partir da Constituição Federal de 1988, que constitui a República brasileira como uma federação trina, ou seja, um pacto entre três entes federados autônomos ${ }^{2}$. Se, por um lado, tal modelo favorece a expressão das especificidades, o que é moderno, de outro, produz tensões na gestão de políticas públicas, que exigem a cooperação intergovernamental ${ }^{3}$.

Essa autonomia também existe na definição da organização do setor público. Assim, neste federalismo sui generis, podemos ter estatutos de servidores e formas de definir o papel dos quadros permanentes e dos cargos de confiança diferentes em cada uma das esferas de governo (Executivo, Legislativo e Judiciário) e diferentes entre os entes federados, ou seja, a União, os 26 estados, o Distrito Federal e os mais de 5.600 municípios. Isso leva a grande disparidade de direitos, salários e requisitos para exercer a função pública, mesmo que regidos todos por uma Lei Maior que exige concurso público para ingresso.

A terceira dimensão importante para a compreensão das características da administração pública brasileira reside no ambiente em que ela se insere, ou seja, no perfil sócio-econômico do País. Os problemas sociais e econômicos, sobretudo o acentuado grau de desigualdade da nossa sociedade, colocam responsabilidades maiores sobre a boa governança. $\mathrm{O}$ que chamamos a atenção é para a necessidade de se desenhar políticas públicas sensíveis a essas diferenças de renda, que contemplem a expressão territorial, assim como a desigualdade de acesso a serviços e direitos.

Atualmente, o Poder Executivo federal está organizado em 30 ministérios, aos quais se vinculam mais de 53 mil órgãos da 
administração direta e indireta ${ }^{4}$, os quais constituem o universo de clientes da ENAP.

Dos cerca de 550 mil servidores civis ativos na administração direta federal, 41,8\% possuem nível de escolaridade superior. Um dos grandes desafios do presente é a idade média elevada desses servidores - 46 anos - que pode ser ainda maior em certas categorias. Nos próximos 11 anos, aproximadamente $70 \%$ dos atuais servidores ativos terão condições de se aposentar, gerando problemas e oportunidades de renovação dos quadros ${ }^{5}$.

Governos nem sempre têm a consciência do papel estratégico dos saberes e conhecimentos de seus servidores para o sucesso das políticas governamentais. Com base em diagnósticos equivocados, como os que vimos nos anos recentes no Brasil, em que se atribuía ao funcionalismo público a causa do endividamento público e a má prestação de serviços, governantes atrasaram a própria construção da nação. O não-investimento regular nos quadros da administração pública reduziu a capacidade de governo.

Contamos, de um lado, com instituições e serviços de excelência como nossa diplomacia, nossas universidades públicas, nossos hospitais-escola e nossos centros de pesquisa de ponta, que atuam e produzem tecnologias e conhecimentos internacionalmente competitivos ${ }^{6}$, provas vivas da qualidade e de anos de investimento na formação de quadros públicos. De outro, ao mesmo tempo, encontramos diversos ministérios esvaziados, sem equipes permanentes, sem processos de trabalho estruturados e sem memória.

Ainda persistem, além disso, o clientelismo, os corporativismos e a ausência de uma burocracia profissionalizada em dimensões adequadas ao Brasil. Esta é a realidade brasileira atual. Heterogênea, como o nosso país.

Mas, sabemos, essa atividade conhecimento-intensiva que é o governar apóiase em servidores públicos. É por isso que este governo afirma o papel estratégico do funcionalismo. As ações que concretizam essa política são a retomada de concursos públicos regulares e a política de capacitação, visando dotar esses quadros de capacidade de formulação, implementação e avaliação de políticas públicas.

Apesar de não termos um funcionalismo muito grande em comparação internacional, o Brasil, hoje, dispõe de pequeno grau de liberdade para ampliar os quadros no curto prazo ou para adequar os salários ao mercado. Acreditamos que, mesmo enfrentando limitações para conceder incentivos econômicos, por restrições orçamentárias e por demanda de investimento em outras prioridades de governo, é necessário e possível motivar nossos servidores públicos com outras formas de incentivo. Destaca-se, neste caso, a capacitação permanente dos servidores.

\section{Desenvolvimento de competências na administração pública brasileira}

Qual o papel da capacitação na criação de riquezas humanas na administração pública brasileira? O que se pode esperar dos servidores públicos em uma sociedade do conhecimento?

O governo do presidente Lula definiu, em seu Plano Plurianual - PPA 2004/2007, três diretrizes: 1) inclusão social e redução das desigualdades sociais; 2) crescimento com geração de trabalho, emprego e renda, ambientalmente sustentável e redutor das desigualdades; e 3) promoção e expansão 
da cidadania e fortalecimento da democracia.

São tarefas que supõem que o trabalho no setor público federal seja excelente. Cada área de recursos humanos deve ser dotada do que necessita, na hora certa, uma realidade ainda distante. Isso exige rever a política de recursos humanos tradicionalmente praticada na administração pública brasileira.

A moderna gestão de pessoas assentase em um tripé estratégico: gestão por competências; democratização das relações de trabalho para gerar ambientes adequados à inovação; e qualificação intensiva das equipes de trabalho, incluindo o uso de tecnologia da informação.

A nova política de capacitação e de desenvolvimento de pessoas (Decreto $\mathrm{n}^{\circ}$ 5.707, de 23/02/2006, que revogou o Decreto no $2.794 / 1998)$, em implantação no governo federal, tem essa visão estratégica. Considera que a gestão de pessoas necessária é aquela que promove a gestão por competências. Desde 2006, esse modelo de gestão é considerado referência-chave. Ainda pouco conhecido no setor público, tanto no Brasil como no mundo, a gestão por competências significa olhar para o trabalho por uma lente que combina os conhecimentos, o saber-fazer, a experiência e os comportamentos exercidos em contexto específico. O foco não mais repousa sobre a atribuição formal de um posto de trabalho. As competências, sabemos, só são constatadas quando utilizadas em situação profissional, a partir da qual são passíveis de validação. Nesse sentido, cada órgão público deve passar a identificálas, avaliá-las, validá-las e fazê-las evoluir. Estamos falando, aqui, de uma mudança radical frente ao modelo tradicional de posto de trabalho.
A nova política também estimula a aprendizagem e a disseminação do conhecimento; atribui ao conhecimento a chave para a inovação e a melhoria da gestão pública; altera a separação entre o decidir e o executar; busca a qualidade de vida no trabalho (saúde física e emocional); valoriza a informação compartilhada; e, finalmente, cria alto grau de envolvimento de dirigentes e de servidores no ambiente de trabalho.

Não se trata de administração de pessoal nem da mera gestão de recursos humanos. Ela visa mudar a gestão pública, inovar e aprimorar nossa capacidade de atender mais e melhor, incluir servidores e mobilizar seus talentos.

A partir dessa visão, o desenvolvimento de profissionais públicos adquire um peso diferente. A aplicação da gestão por competências tem potencial em todo o ciclo de ações da gestão de pessoas, ou seja, seleção, alocação, desenvolvimento e avaliação de desempenho.

A nova política e a aposta da Escola Nacional de Administração Pública - ENAP

O Decreto 5.707/06 é inovador pelos conceitos que utiliza. Considera capacitação como um processo permanente e deliberado de aprendizagem para o desenvolvimento de competências institucionais e individuais. Coloca o foco da capacitação na melhoria da eficiência e da eficácia do serviço público. Propõe, como já falamos, nova abordagem, a gestão por competências, as quais devem ser adequadas aos objetivos institucionais, tendo como referência o Plano Plurianual de governo. Prevê, ainda, a divulgação e o gerenciamento das ações de capacitação.

Sua visão dos "espaços para aprender", ou seja, do que se configura como "eventos 
de capacitação" é abrangente, abarcando: cursos presenciais e a distância, aprendizagem em serviço, grupos formais de estudos, intercâmbios, estágios, seminários e congressos.

Nessa política, é prioridade a adoção de novos métodos de ensino, voltados para sensibilizar e incentivar novas práticas de trabalho no serviço público, em velhas e novas gerações de servidores.

A formação de parcerias e a articulação de uma rede nacional de escolas de governo constituem, de outra parte, seus pilares. Destaca-se, aqui, em particular, a Rede Nacional de Escolas de Governo ${ }^{7}$. No Brasil, a capacitação dos servidores públicos é desenvolvida no governo federal, nos governos estaduais e municipais, por entes que vão de escolas de governo com regime jurídico, infraestrutura e orçamentos próprios, até unidades de recursos humanos subordinadas a secretarias de administração e planejamento de governos estaduais ou municipais. Buscando atingir toda essa diversidade de instituições, foi formada, em 2003, por iniciativa da ENAP, a Rede Nacional de Escolas de Governo, que tem procurado viabilizar o estabelecimento de contatos mais estreitos por meio de cooperações e parcerias para o desenvolvimento de projetos conjuntos entre as escolas de governo.

A nova política convida os ministérios a elaborar planos de capacitação reais e não burocráticos. Torna, ainda, explícita a obrigação de fortalecimento das áreas de desenvolvimento de pessoas, conforme previsto em seu art. $12^{8}$.

Para atingir tais objetivos, a nova política confere importância grande à capacitação gerencial e qualificação para ocupação dos cargos de Direção e Assessoramento Superiores. Trata-se, desta forma, de uma política claramente orientada para a profissionalização do serviço público federal. Paralelamente, a política de gestão de pessoas da atual administração busca a valorização do servidor, sendo revistas as políticas de seleção, de remuneração, de avaliação de desempenho e de capacitação.

Uma estratégia de apoio à implementação da gestão por competências foi

"O modelo de gestão por competências

aumenta a

responsabilidade dos

dirigentes. Saber lidar

com a incerteza,

correr riscos,

aprender

coletivamente,

questionar-se e mudar

o modo de encarar as

vantagens

proporcionadas pela

experiência são

algumas de suas

implicações."

desenhada, sob a coordenação do Comitê Gestor da Política Nacional de Desenvolvimento de Pessoal, cuja criação está prevista no art. $7^{\circ}$ do Decreto no 5.707/06. Esse comitê é leve, formado pelos secretários da Secretaria de Recursos Humanos, Secretaria de Gestão, do Ministério do Planejamento, Orçamento e Gestão, e pelo presidente da ENAP. Esperase que seja capaz de apoiar e orientar as ações de capacitação, assim como incentivar 
as iniciativas de capacitação promovidas pelas próprias instituições e a ampla divulgação das oportunidades.

Cabe ao comitê avaliar os relatórios anuais dos órgãos e entidades, verificando se foram observadas as diretrizes da Política Nacional de Desenvolvimento de Pessoal; orientar os órgãos e entidades da administração pública federal direta, autárquica e fundacional na definição sobre a alocação de recursos para fins de capacitação de seus servidores; e promover a disseminação da Política Nacional de Desenvolvimento de Pessoal entre os dirigentes dos órgãos e das entidades, os titulares das unidades de recursos humanos, os responsáveis pela capacitação, os servidores públicos federais e suas entidades representativas.

Nos primeiros meses de seu funcionamento em 2006, o comitê gestor decidiu:

a) oferecer cursos de curta duração para segmentos estratégicos à implantação da nova política, a saber: os subsecretários de Planejamento e Orçamento dos ministérios (SPOA) e seus adjuntos; os diretores de secretarias setoriais responsáveis pela capacitação, no âmbito dos programas do PPA; e os coordenadores de recursos humanos. A meta será de $20 \mathrm{~h} /$ ano para os SPOA e adjuntos e de $60 \mathrm{~h} /$ ano para os coordenadores de RH, em 2007;

b) criar curso semi-presencial de Especialização em Gestão de Pessoas, a ser oferecido a partir do segundo semestre de 2007;

c) oferecer oficinas de mapeamento de competências para qualificar a elaboração de planos de capacitação durante o primeiro semestre de 2007;

d) divulgar e oferecer bolsas a servidores lotados nas coordenações de recursos humanos nos curso de Especialização em Gestão Pública da ENAP, desde que aprovados no processo seletivo; e) organizar conferência sobre gestão por competências, em 2007, incentivando a inscrição de trabalhos com relatos de experiências concretas, bem ou mal sucedidas na administração pública federal;

f) oferecer seminários, por meio da cooperação técnica internacional da ENAP, sobre o desenvolvimento de pessoas em 2007;

g) aprovar a oferta de curso de Especialização em Gestão de Pessoas (segundo semestre de 2007);

h) realizar seleção pública de oportunidade de capacitação internacional - por exemplo, os cursos oferecidos pela JICA (Agência Japonesa de Cooperação Internacional) - para servidores da área central do sistema (SRH, SEGES e ENAP).

À ENAP, cabe o papel estratégico de formação de quadros dirigentes, buscando dotar o Estado brasileiro de técnicos capazes de assumir postos de alta responsabilidade. Iniciativa, inovação, criatividade são alguns dos atributos que queremos desenvolver em conjunto com esses servidores.

A missão de desenvolver as competências de dirigentes e equipes de servidores não é novidade para a ENAP. Ela foi definida em 2003, antes, portanto, do decreto e coloca, desde então, desafios para a atuação da escola.

O primeiro deles relaciona-se às implicações de se trabalhar com o conceito de competências. A literatura sobre gestão de pessoas tem abordagens bastante diversas à gestão por competências. Não apresenta, contudo, estudos aplicados ao setor público, tampouco relata experiências concretas sobre as formas de capacitar dentro desse modelo, em particular quando se trata de competências relacionais ou pessoais.

Competência pode ser definida como o "tomar iniciativa" e o "assumir responsabilidade" do indivíduo diante das situações 
profissionais com as quais se depara (ZARIFIAN, 2001). É um aprendizado que engloba entendimento prático, apoiado em conhecimentos adquiridos. Ela se transforma e se aplica a uma diversidade de situações e pode gerar novos conhecimentos.

A gestão por competências exige atenção prioritária aos aspectos qualitativos do investimento em pessoas e deve ser utilizada para a seleção de pessoas, para o planejamento de carreiras, para a gestão de desempenho e para o desenvolvimento pessoal. Com isso, traz um novo papel para o desenvolvimento de profissionais (gestão do desenvolvimento), o desenvolvimento de competências "na" organização e "sobre" a organização.

A principal conseqüência desse modelo de gestão é o aumento da responsabilidade dos dirigentes. Saber lidar com a incerteza, correr riscos, aprender coletivamente, questionar-se e, sobretudo, mudar o modo de encarar as vantagens proporcionadas pela experiência são algumas implicações da gestão por competências. Também, é essencial combinar, de forma flexível, competências individuais em redes de trabalho e conferir papel estratégico à sistematização dos processos de aprendizagem. A grande referência para a ação coletiva não é a descrição das atribuições do órgão, mas a visão compartilhada, o sentido comum do trabalho.

Ora, esses conceitos são estranhos à administração pública, orientada tradicionalmente por regras rígidas e com pouquíssimo espaço para experimentação.

O governo dos EUA, segundo estudos da OCDE, definiu um rol de competências nucleares para executivos públicos (qualificações específicas para os postos de trabalho e qualificações gerais), no qual aparecem: capacidade de liderar mudanças; capacidade de liderar pessoas; orientação para resultados; conhecimentos em gestão de pessoas, capacidade de gestão financeira e gestão de tecnologia de informação; e capacidade de construção de alianças e comunicação.

No Reino Unido, por sua vez, foram definidas competências de líderes orientados para resultados, a saber: criar e comunicar visão de futuro; motivar e desenvolver pessoas para obter alto desempenho; liderar pelo exemplo; empregar a experiência e novas idéias para melhorar resultados; e pensamento estratégico para atingir objetivos.

A ENAP bebe da fonte da profícua cooperação com o governo do Canadá, por meio da nossa parceira, a Escola Canadense do Serviço Público (Canada School of Public Service), para definir as competências essenciais a serem desenvolvidas nos nossos cursos. Por meio dela, adaptamos cursos voltados para o desenvolvimento de competências, como a liderança, e debatemos quais as competências críticas para a gestão pública brasileira.

No Canadá, essas competências compreendem: as competências intelectuais, que se referem à capacidade cognitiva e à criatividade; o desenvolvimento futuro de competências, que se traduz na visão do futuro; e as competências de gestão, entre as quais se encontram a gestão-ação, a consciência organizacional, o trabalho em equipe e o desenvolvimento de parcerias. Priorizam-se, também, competências relacionais (relações interpessoais e comunicação) e competências individuais (resistência ao estresse, ética e valores, personalidade, flexibilidade comportamental e autoconfiança).

O processo de construção desse quadro, no âmbito da direção da escola, foi particularmente rico. Constatou-se que, para podermos ensinar competências de 
A ENAP definiu suas competências existentes ou a desenvolver em quatro classes:

\begin{tabular}{|c|c|}
\hline Classes & Competências \\
\hline Fundamentais/genéricas & $\begin{array}{l}\text { Comprometimento com o serviço público } \\
\text { Trabalho em equipe } \\
\text { Flexibilidade } \\
\text { Sensibilidade social } \\
\text { Negociação } \\
\text { Comunicação }\end{array}$ \\
\hline Organizacionais & $\begin{array}{l}\text { Conhecimento da administração pública } \\
\text { Capacidade de aprender } \\
\text { Comunicação } \\
\text { Negociação } \\
\text { Planejamento educacional } \\
\text { Metodologias de ensino } \\
\text { Prospecção de conhecimentos em gestão pública } \\
\text { Gestão de escola de governo } \\
\text { Conhecimentos de ferramentas de TI e sistemas governamentais }\end{array}$ \\
\hline Gerenciais & $\begin{array}{l}\text { Liderança inspiradora } \\
\text { Senso de direção } \\
\text { Comprometimento } \\
\text { Gestão integrada e estratégica de recursos (capacidade de planejamento) } \\
\text { Visão/mente aberta } \\
\text { Capacidade de análise e síntese } \\
\text { Implementação equilibrada das políticas públicas } \\
\text { Gestão de pessoas }\end{array}$ \\
\hline Pessoais e interpessoais & $\begin{array}{l}\text { Expansão contínua das fronteiras pessoais } \\
\text { Capacidade de articulação } \\
\text { Resolução de problemas } \\
\text { Iniciativa } \\
\text { Cooperação }\end{array}$ \\
\hline
\end{tabular}

direção na administração pública federal, precisaríamos contar com servidores e servidoras que já apresentassem essas competências. Como em todas as experiências conhecidas, essas são as competências desejadas. Em parte, já as detemos, em parte teremos de desenvolvê-las.
Capacitar para o desenvolvimento de competências constitui uma mudança significativa na atuação de escolas de governo. O foco, antes dado às atribuições de cada posto de trabalho, passa a ser dado agora ao desenvolvimento do profissional em sintonia com a atuação da organização. Isso 
implica também desafios metodológicos, porque as tradicionais aulas magistrais servem, fundamentalmente, para que os grandes mestres exponham suas teorias, mas não dão conta de preparar profissionais para agir e decidir em condições de incerteza e de grande responsabilidade.

Explicitamos, a seguir, o método que a ENAP vem adotando para desenvolver competências de servidores, tomando como exemplo o tema da liderança.

A escolha desse tema justifica-se por atingir diretamente o público-alvo da escola, que forma os quadros de Direção e Assessoramento Superiores do governo federal, assim como as carreiras estratégicas do ciclo de gestão9 . Trata-se de profissionais que precisam contribuir para o desenho e a consolidação das instituições voltadas para a governança democrática, saber lidar com a diversidade e estimular a cooperação intergovernamental.

O tema desperta reações variadas nos servidores públicos brasileiros: há um temor de que se esteja falando de liderança carismática ou de importação de modismos dos Estados Unidos ou do setor privado.

$\mathrm{Na}$ ENAP, trabalhamos com o conceito de "liderança responsável", que abarca não apenas os cargos mais altos de direção, mas também assessores, equipes e outros níveis de direção das organizações públicas. Vemos o líder como aquele capaz de entender os diversos desafios que lhe são colocados: de inserir a administração pública nacional em um mundo globalizado; de lidar com a crescente complexidade de cada decisão pública; de enfrentar desigualdades; de lidar com as diferenças de gênero; de incorporar o tema da diversidade; de praticar a boa governança; de aumentar a capacidade de governo; e de contribuir para as necessárias reformas (SCHWELLA, 2005).
A literatura sobre o tema vem crescendo, assim como a experiência de oferta de cursos de liderança para dirigentes públicos em todo o mundo, destacandose o Canadá, os Estados Unidos, a Irlanda e o Reino Unido. Trata-se de um novo desafio de ensino e aprendizagem: as dimensões de auto-conhecimento, autoregulação, motivação, empatia e comunicação social exigem novos métodos de ensino, diferentes das tradicionais aulas expositivas.

Não é tarefa simples nem trivial formar lideranças para as distintas realidades da administração pública brasileira, formada de quadros heterogêneos, diferenças culturais e geracionais, caracterizada por um federalismo de conflitos e não de cooperação ou de subsidiariedade. Por essas razões é que as competências a serem desenvolvidas em complemento à liderança são a escuta ou a comunicação, a formação de consensos e a negociação.

Além disso, entendemos que as lideranças no setor público precisam ser capazes de lidar tanto com problemas estruturados como com problemas complexos, para os quais é preciso ter capacidade de adaptação, de reflexão e de estímulo ao aprendizado. O desafio está, sobretudo, em conseguir oferecer formas de aprendizado voltadas para reflexão, criatividade e iniciativa de modo a contribuir para a preparação de servidores capazes de agir, tomar decisões e melhorar a gestão pública no país.

Os cursos da ENAP combinam exposição dialogada de modelos conceituais, simulações, grupos de discussão e exercícios de visualização. Utilizam-se também estudos de caso e oficinas cujo objetivo primordial é o de favorecer a troca de experiências entre os profissionais públicos. 


\section{Cenários e perspectivas}

Para concluir, delineamos alguns cenários e perspectivas para o desenvolvimento de competências. O ambiente, marcado, ao mesmo tempo, pela riqueza da diversidade e por grandes desigualdades, impõe-nos constante análise de necessidades futuras de competências na administração pública para a realidade nacional.

Ao analisar o perfil que os Especialistas em Políticas Públicas e Gestão Governamental, os chamados gestores, deverão ter no futuro, Ferrarezi e Zimbrão (2006) tratam também das competências necessárias a dirigentes públicos em geral para lidar com as mudanças constantes na(s) realidade(s) brasileira(s). Eles precisam ser capazes de avaliar riscos, fazer julgamentos com precisão e agilidade, reconhecer problemas e interesses, gerenciar diversidade de atores envolvidos, negociar e gerenciar acordos, repactuar regras, conhecer mercados, escutar, ter consciência dos limites, escolher técnicas, métodos e tecnologias e gerenciar ajustes.
$\mathrm{Na}$ visão da ENAP, entre as competências a desenvolver no futuro, destaca-se o foco permanente nos princípios da eqüidade e da democracia. Queremos, também, ajudar a formar servidores capazes de agir como "tradutores culturais", capazes de compreender diferentes funcionamentos e lógicas e de dialogar com as múltiplas identidades societárias, com atenção especial às questões de raça e de gênero.

O grande desafio é fazer com que a atividade pública seja cada vez mais inovadora. Sem perder de vista os princípios da legalidade e da impessoalidade, sermos capazes de ouvir a sociedade, experimentar e construir um serviço público com homens e mulheres responsáveis, criativos e com alta capacidade de responder a problemas públicos - tanto os velhos como os que nem ousamos a pensar que virão.

(Artigo recebido em novembro de 2006. Versão final em dezembro de 2006)

\section{Notas}

\footnotetext{
${ }^{1}$ Kerche diz que "embora os cargos de confiança sejam de livre provimento, a grande maioria é ocupada por servidores concursados pertencentes ao quadro funcional do Estado brasileiro, mesmo nos mais altos escalões. A maioria dos DAS, na prática, funciona como uma espécie de gratificação ao funcionário público por exercer momentaneamente uma função de confiança no governo.(...) Desde 2005, por meio de decreto assinado pelo presidente Lula, $75 \%$ dos DAS de um a três e $50 \%$ dos DAS 4 - que, no total, representam $94,5 \%$ dos cargos de livre provimento - devem, necessariamente, ser ocupados por funcionários de carreira. O governo limitou seu verdadeiro livre provimento - poder escolher qualquer cidadão, servidor público ou não, para ocupar um posto no governo federal - a apenas $32,5 \%$ do total de DAS na estrutura do Executivo. Dito de outra forma, o governo Lula retirou de sua absoluta discricionariedade a nomeação de mais de 13.300 cargos. Dos 520 mil servidores públicos civis na ativa do Poder Executivo, pouco mais de 6.400 , ou 1,2\%, podem ser livremente indicados para servir ao governo por determinado período sem necessidade de ter passado
} 
por concurso público. Ou seja, 98,8\% dos cidadãos que ocupam postos de trabalho no Poder Executivo federal são, necessariamente, funcionários públicos de carreira e passaram por concurso público".

${ }^{2}$ Art. 18 da Constituição Federal : "A organização político-administrativa da República Federativa do Brasil compreende a União, os Estados, o Distrito Federal e os Municípios, todos autônomos".

${ }^{3}$ Em “Os desafios federativos" (Revista do Serviço Público, vol. 56, n 1, jan-mar de 2005), o subsecretário de Assuntos Federativos da Presidência da República, Vicente Trevas, mostra que as singularidades da federação brasileira podem ser compreendidas historicamente. Para o subsecretário, "a federação foi sempre um mecanismo compensatório para que a corda não esticasse a ponto de romper, ou seja, uma equação para compensar desigualdades e reproduzir os interesses do grupo dominante e dos grupos subalternos oligárquicos".

4 Informações disponíveis em <www.brasil.gov.br/estrutura.htm> e no Sistema de Informações Organizacionais do Governo Federal (Siorg), em: <www.siorg.redegoverno.gov.br>. Acesso em: 15 dez. 2006.

${ }^{5}$ Boletim Estatístico de Pessoal. Jul. 2006. Disponível em <www.servidor.gov.br>, em publicações. Acesso em: 15 dez. 2006.

${ }^{6}$ São exemplos: o sistema eleitoral brasileiro, inteiramente automatizado, que atende a todos os municípios brasileiros e um universo de 108 milhões de eleitores; a atuação da Embrapa (Empresa Brasileira de Pesquisa Agropecuária), que possibilita as atuais vantagens comparativas do agronegócio brasileiro no mercado mundial; e a tecnologia de prospecção de petróleo em águas profundas, desenvolvida pela Petrobras.

${ }^{7}$ Mais informações em: <www2.enap.gov.br/rede_escolas>.

${ }^{8}$ Art. 12 do Decreto 5.707/2006: "Os órgãos e entidades deverão priorizar, nos dois primeiros anos de vigência deste Decreto, a qualificação das unidades de recursos humanos, no intuito de instrumentalizá-las para a execução das ações de capacitação".

${ }^{9}$ Entre as quais se englobam as carreiras de Especialista em Políticas Públicas e Gestão Governamental (EPPGG) e Analista em Planejamento e Orçamento(APO), cuja formação inicial se dá na ENAP.

\section{Referências bibliográficas}

Amaral, H.K ; Licio, E.C. Potencialidades para aumentar a capacidade de governo no Brasil. Teknee - Revista de Estudos Politécnicos, Portugal: n 1, 2004.

Amaral, H.K. Conexões estratégicas para o aumento da eficácia das ações de capacitação de dirigentes públicos. In: CLAD, 2004. Madri: novembro, 2004.

Carvalho, P.S. Escolas de Governo e Cooperação. In: CLAD, 2005. Santiago, Chile: outubro, 2005. 
Faoro, R. Os Donos do Poder: a formação do patronato brasileiro São Paulo: Ed. Globo, $3^{\mathrm{a}}$ ed, 2001.

FERrareZi, E.; Zimbrão, A. Formação de carreiras para a gestão contemporânea: o caso dos Especialistas em Políticas Públicas e Gestão Governamental, in Revista do Serviço Público, v. 57, n. 1, jan./mar. 2006.

Kerche, F.Aparelhamento do Estado?. Folha de S.Paulo, 28 set. 2006, p.3.

Karmack, E. Government Innovation Around the World. Faculty Research Working Papers Series, RWP04-010, Ash Institute for Democratic Governance and Innovation, Kennedy School of Government, Harvard, 2004.

SCHWELla, E. "Inovação no governo e no setor público: desafios e implicações para a liderança”, in Revista do Serviço Público, v. 56, n. 3, jul./ set. 2005.

Trevas, V. Os desafios federativos, in Revista do Serviço Público, v. 56, n. 1, jan./mar. 2005. ZARIFIAN, P. Valor, organização e competência na produção do serviço - esboço de um modelo de produção de serviço. In: SALERno, M.S. Serviço: produção, desempenho e trabalho. São Paulo: Senac, 2001. 


\section{Resumo - Resumen - Abstract}

\section{Desenvolvimento de competências de servidores na administração pública brasileira} Helena Kerr do Amaral

Este artigo trata dos desafios de desenvolver as competências de servidores, de forma a melhorar a capacidade de governo na gestão das políticas públicas no Brasil. Na primeira parte, apresenta as características da administração pública brasileira em três dimensões: o modelo de carreiras dos servidores, o tipo de federalismo do País e o ambiente sócio-econômico em que opera. Em seguida, analisa a nova política de desenvolvimento de pessoal (Decreto $n^{\circ} 5.707 / 2006$ ), que tem como foco a gestão por competências, e o papel da ENAP na formação e capacitação de dirigentes e servidores. Ao final, lança um desafio para a administração: a construção de um serviço público altamente capacitado e inovador, que atue dentro dos princípios da legalidade e da impessoalidade.

Palavras-chave: servidor público; capacitação; competências.

\section{Desarrollo de competencias de servidores en la administración pública brasileña} Helena Kerr do Amaral

Este artículo trata de los retos de desarrollar las competencias de los servidores públicos, de forma a fortalecer la capacidad de gobierno en la gestión de las políticas públicas en Brasil. En la primera parte, se presentan los rasgos de la administración pública brasileña en tres dimensiones: el modelo de carrera de los servidores, el tipo de federalismo en Brasil y el ambiente socio-económico en que opera la administración. A continuación, analiza la nueva política de desarrollo de personal (Decreto 5.707/2006), que tiene como foco la gestión por competencias, y el rol de ENAP en la formación y capacitación de los directivos y servidores. Por fin, presenta un desafío a la administración: la construcción de un servicio público altamente capacitado e innovador, que actúe dentro de los principios de la legalidad y de la impersonalidad.

Palabras clave: servidores públicos; capacitación; competencias.

\section{Developing competencies of public servants in the Brazilian public administration}

Helena Kerr do Amaral

This article presents the challenges of developing the competencies of public servants in order to increase government capacity to manage public policies in Brazil. In the first part, it highlights the characteristics of the Brazilian public administration considering three dimensions: the public career framework, the Brazilian federalism, and the social and economic environment in which it operates. It then analyzes the new personnel development policy (Decree 5.707/2006), which focuses on the competency management, and the role ENAP plays in the capacity building and the training of public managers and servants. It concludes by posing a challenge for the public administration: to build a well trained and innovative public service acting in accordance with the principles of lawfulness and impersonality.

Key words: public servants; capacity building; competencies.

Helena Kerr do Amaral é presidente da ENAP desde 2003.

Contato: <ap@enap.gov.br> 